\title{
The Importance of Videofluoroscopic Swallowing Study in Patients with Pneumonia
}

Won-Jae Jo, M.D, Ki-Pi Yu Ph.D, Yu-Hyun Lim Ph.D, Departments of Physical Medicine and Rehabilitation, Presbyterian(Jesus) Medical Center

\section{Introduction}

- Aspiration pneumonia is diagnosed when patients exhibit obvious aspiration or symptoms such as sudden onset of dyspnea, cyanosis and/or radiographic evidence of an infiltrate in a characteristic bronchopulmonary segment.

- Video Fluoroscopic Swallowing Study(VFSS) is the gold standard method to evaluate the swallowing function and important to determine the proper treatment in patients with aspiration pneumonia.

- We investigate the results of the VFSS and outcomes in the patients with pneumonia or aspiration pneumonia and figure out the meaning of VFSS in pneumonia patients without aspiration symptom.

\section{Methods}

Inclusion criteria

$\begin{array}{ll}\text { (1) Age }>65 \text { years old } \\ \text { (2) Diagnosed with pneumonia or aspiration pneumonia } \\ \text { (3) } & \text { Received VFSS From April } 2016 \text { to February } 2017\end{array}$

Assessment

- $\quad$ Sex

- Aspiration symptom

- Oral phase problem

- Vallecula residue, Pyriform sinus residue

- Cough reaction

- Penetration - Aspiration Scale(PAS) scores

- Modification of the feeding method based on VFSS

- Existence of recurrence

: Readmission due to recurrence of pneumonia

: Readings of chest $\mathrm{x}$-ray and Symptom

\section{Figure 1. Patients Flow Chart}

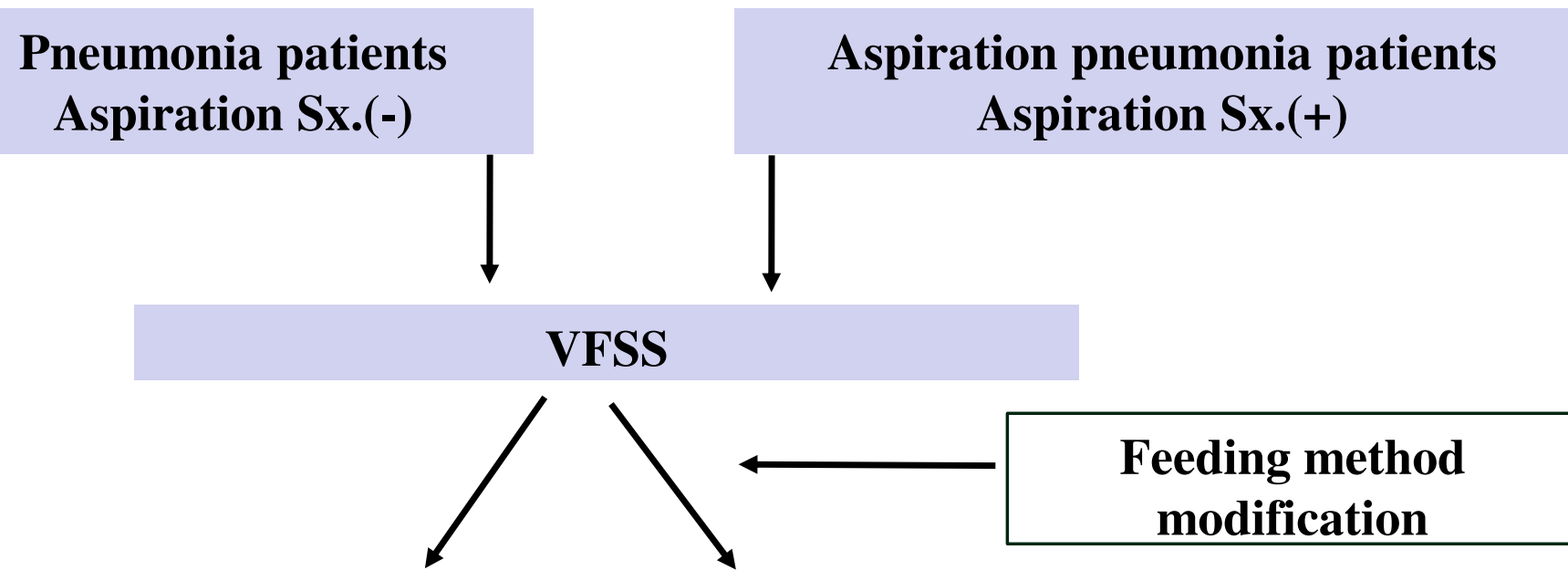

Oral feeding Nasogastric tube(NGT) feeding

Recurrence (+) Readmission

Recurrence (-)

Table 1. Baseline characteristics

\begin{tabular}{|c|c|} 
Characteristic & $\begin{array}{c}\text { Value } \\
(\mathrm{n}=94)\end{array}$ \\
\hline Sex (Male $:$ Female) & $58: 36$ \\
\hline Oral phase problem $(+:-)$ & $71: 23$ \\
\hline Residue $(+:-)$ & $33: 61$ \\
\hline Cough reaction $(+:-)$ & $87: 7$ \\
\hline
\end{tabular}
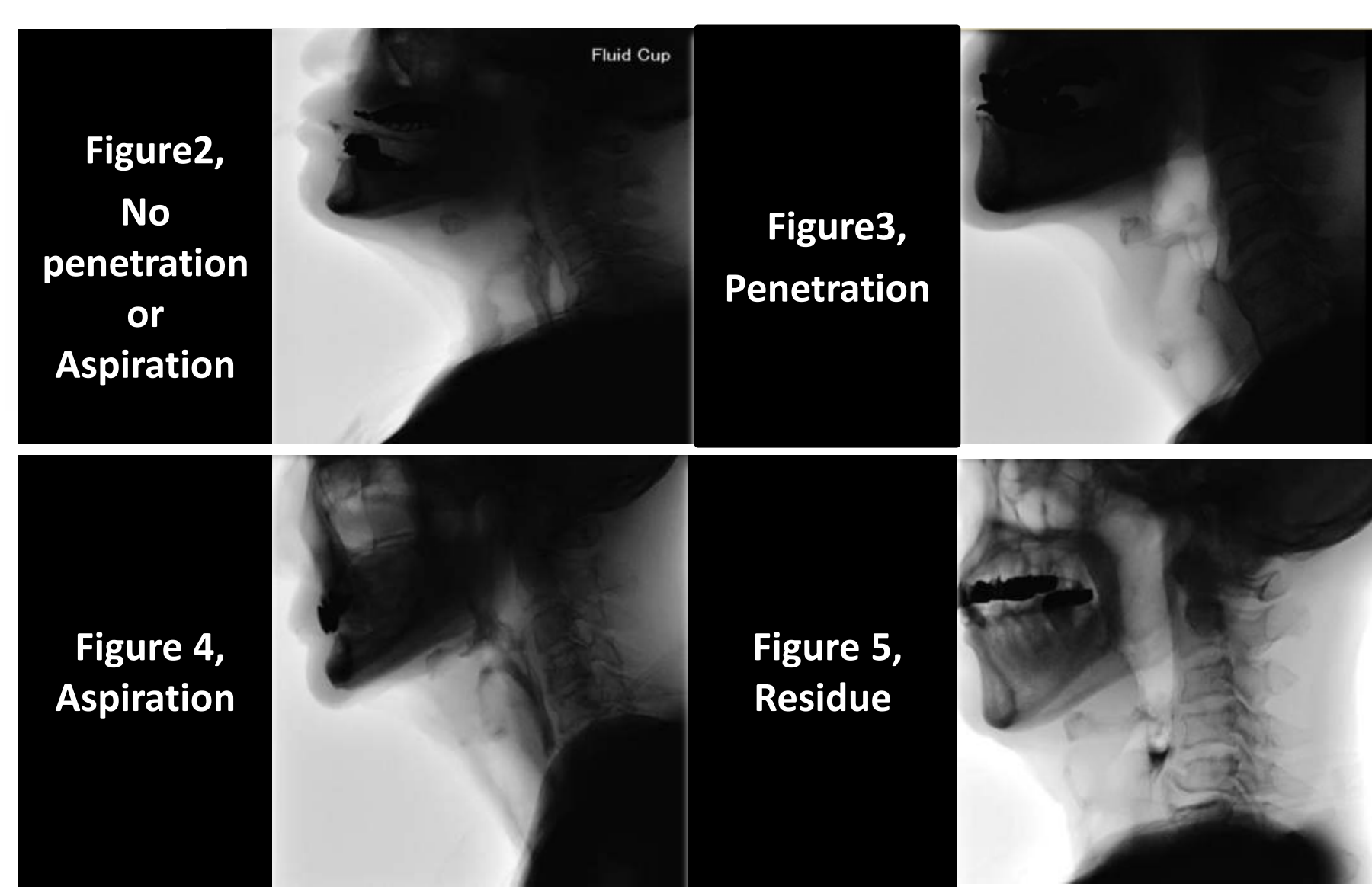

Table 2. Modification of the feeding method based on VFSS

\begin{tabular}{|c|c|l|}
\hline \multicolumn{2}{|l|}{ Total patients } & $\mathrm{n}=94$ \\
\hline \multicolumn{2}{|c|}{ Patients with aspiration pneumonia } & 35 \\
\hline Before VFSS & After VFSS & \\
\hline \multirow{2}{*}{ NPO, NGT feeding } & Oral feeding & $13(37.1 \%)$ \\
\cline { 2 - 3 } & NGT feeding & $10(28.6 \%)$ \\
\hline \multirow{2}{*}{ Oral feeding } & Oral feeding & $12(34.3 \%)$ \\
\cline { 2 - 3 } & NGT feeding & $0(0.0 \%)$ \\
\hline Patients with pneumonia & & 59 \\
\hline Before VFSS & After VFSS & $11(18.6 \%)$ \\
\hline \multirow{2}{*}{ NPO, NGT feeding } & Oral feeding & $14(23.7 \%)$ \\
\cline { 2 - 3 } & NGT feeding & $30(50.8 \%)$ \\
\hline \multirow{2}{*}{ Oral feeding } & Oral feeding & $4(6.8 \%)$ \\
\cline { 2 - 3 } & NGT feeding & \\
\hline
\end{tabular}

Table 3. Progress after discharge

\begin{tabular}{|c|c|}
\hline Total patients & $\mathrm{n}=94$ \\
\hline Patients with aspiration pneumonia & 35 \\
\hline Recurrence of pneumonia(-) & $14(40.0 \%)$ \\
\hline Recurrence of pneumonia(+) & $3(8.6 \%)$ \\
\hline Loss of follow up & $18(51.4 \%)$ \\
\hline Patients with pneumonia & 59 \\
\hline Recurrence of pneumonia(-) & $32(54.2 \%)$ \\
\hline Recurrence of pneumonia(+) & $3(5.1 \%)$ \\
\hline Loss of follow up & $22(37.3 \%)$ \\
\hline Expire during admission & $2(3.4 \%)$ \\
\hline
\end{tabular}

\section{Result}

- In patients with pneumonia, 18.6\% $(\mathrm{n}=11)$ patients removed NGT and was changed to oral feeding after VFSS.

- Among patients diagnosed pneumonia without aspiration symptom, 4 patients had aspiration sign in VFSS and was changed to NGT feeding after VFSS.

\section{Conclusion}

-We assume that even in patients with pneumonia who do not have aspiration symptom may have silent aspiration pneumonia.

- We conclude that VFSS is important in patients who were diagnosed pneumo nia without aspiration symptom as well as in the patients with aspiration pneum onia to prevent the recurrence of pneumonia by modifying the feeding method. 